\title{
TCU INSTITUTIONAL REVIEW BOARD
}

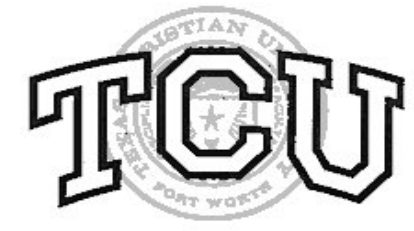

\section{REQUEST FOR AMENDMENT/MODIFICATION TO PROTOCOL}

The TCU Institutional Review Board (IRB) is responsible for protecting the welfare and rights of individuals who are subjects of any research conducted by faculty, staff, or students at TCU. Approval by the IRB must be obtained prior to any amendment/ modification to the original protocol.

Date: $08 / 05 / 2014$

1. Project Title: Comparative effects of post-exercise ingestion of a high or low molecular weight solution on resistance exercise performance

IRB Initial Approval Number and Date: 1401-45-1401 January 31 ${ }^{\text {st }}, 2014$

2. List the name and Faculty/Students/Staff status of the person(s) conducting the research.

a. Principal Investigator: Jonathan M. Oliver

b. Department: Kinesiology

c. Others: Joel Mitchell, Melody Phillips, Leighsa Brace, Torie Johnson

3. Project Period: $01.22 .14-01.22 .15$

4. $\quad$ Funding

a. Agency: Vitargo Global Sciences, LLC

b. Amount Awarded: $\$ 12,000$

5. Summarize the amendment/modifications.

Payment will be provided for those participants that complete the study in the amount of $\$ 250$.

6. Does this amendment/ modification impact the level of risk? Yes / No If yes, how? No

Preparer's Name $\frac{\text { Jonathan Oliver }}{\text { Printed }}$

Date: $08 / 05 / 2014$

TCU Box 297730

Ext. 5623

Email Address: jonathan.oliver@tcu.edu 